\title{
The National Average is D: Who is to Blame?
}

\author{
Janet M. Collie-Patterson ${ }^{1}$
}

\begin{abstract}
The publishing of the Bahamas General Certificate of Secondary Education (BGCSE) 2005 examination results sparked considerable public debate about the national average being a D. Much of the debate was focused on the teacher and the school whilst very little was said about the other contributors to achievement in education.

In a survey of 1,036 students and 52 teachers from public and private schools in New Providence, Bahamas, conducted in the spring semester of 1999, Collie-Patterson (1999) found the students' characteristics consisting of prior ability, attitude toward school, socioeconomic status and parental involvement made the largest contribution (60\%) to mathematics achievement. Taken individually, the effect size indicated that students' prior ability made the largest contribution (45\%) to mathematics achievement. The set of teachers' characteristics, including professional development, teaching experience, and education background were significantly related to mathematics achievement but contributed only $8 \%$ to students' mathematics achievement. The set of classroom characteristics contributed $35 \%$ and the set of school characteristics contributed $12 \%$ to mathematics achievement.

The purpose of this paper is to analyse the factors that could potentially influence student performance in mathematics which greatly affects the national average due to the large number of students taking the mathematics examination and the low grade point average attained in that examination.
\end{abstract}

\section{INTRODUCTION}

In the wake of the publishing of the Bahamas General Certificate of Secondary Education (BGCSE) 2004-05 examinations results, there was much public debate about the national average of $\mathrm{D}$ but until there is improvement in the execution of the roles played by the various contributors in our educational system this will, perhaps, remain unchanged.

The BGCSE curriculum consists of two levelscore and extended. Students who take the core curriculum can receive grades $\mathrm{C}$ to $\mathrm{U}$, while the students who take both the core and extended curriculum can receive grades $A$ to $U$. It is important that we determine what is a D in the BGCSE examination. While the numerical score of a D is confidential, we know that a $\mathrm{C}$ at BGCSE shows competency in the core curriculum. This implies that students achieving a $\mathrm{D}$ are not competent in the core curriculum. While most of this debate focused on the average grade, little of the debate was focused on who contributed to that average grade. This fundamental premise aside, the purpose of this paper is to analyse the factors that could potentially influence the students' performances in such circumstances. In addition, although the national average is purportedly calculated on grades obtained by students taking all the subjects

\footnotetext{
${ }^{1}$ Janet M. Collie-Patterson, Department of Mathematics, School of Science and Technology, The College of The Bahamas, P.O. Box N-4912, Nassau, Bahamas.

E-mail: jpatterson@cob.edu.bs
}

How to cite this article in APA (7th ed.) style: Collie-Patterson, J. M. (2008). The national average is D: Who is to blame? The College of The Bahamas Research Journal, 14, 28-37. https://doi.org/10.15362/ijbs.v14i0.102 
in the BGCSE, the focus of this paper will be primarily on students' achievement in mathematics. There are two main reasons for this focus. Traditionally, student performance in mathematics has been lower than most other subject areas; and there is a larger number of students writing the mathematics examination since the majority of students are required to take both mathematics and English. In 2005 the average for the BGCSE mathematics examination was $\mathrm{E}+$, one of the lowest average performances in any of the national examinations. That year, 5,762 students wrote the BGCSE exams (Pinder, 2005) of which 4,277 wrote the mathematics exam. (Ministry of Education, Science and Technology, 2005). As a result, the low average score in mathematics could significantly impact the overall national average.

According to the 2005 results, 4,277 students wrote the BGCSE mathematics examination. Of the number taking this examination, $2.2 \%(n=94)$ received a grade of $A ; 2.92 \%(n=125)$ received a grade of $B ; 20.34 \%(n=870)$ received a grade of C; $15.1 \%(n=646)$ received a grade of $D ; 16.62 \%$ $(n=711)$ received a grade of $E ; 15.2 \%(n=650)$ received a grade of $F ; 15.01 \%(n=642)$ received a grade of $\mathrm{G}$; and $12.6 \%(\mathrm{n}=539)$ received a grade of $U$ with the national average for mathematics being E+. (See Figure 1).

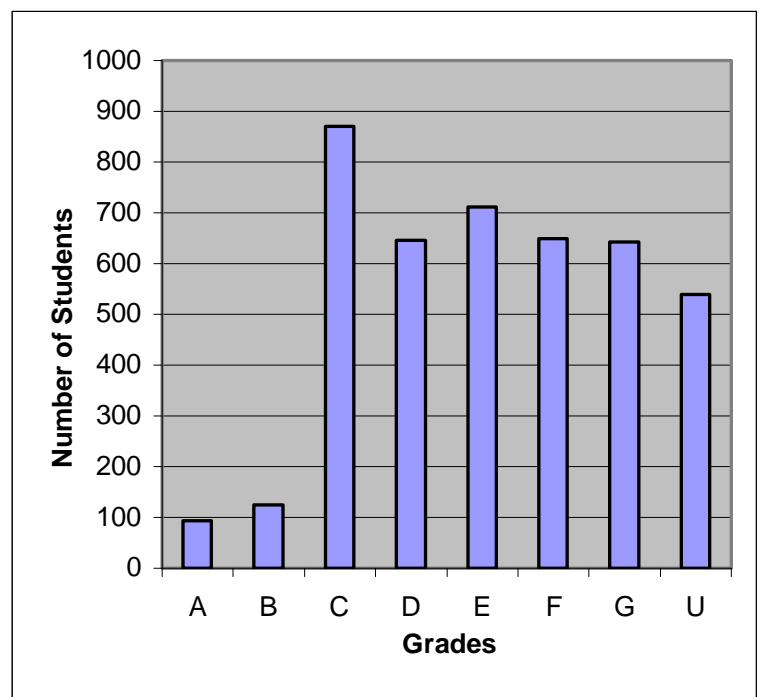

Figure 1. BGCSE 2005 Mathematics Results

In the instance of the BGCSE 2005 examination results, the majority of the pundits tend to place the blame on the school-mainly the teachers.
Such a conclusion, of course, dismisses the fact that although the school plays an important role in students' achievement, many other factors are involved, particularly when we consider the players in the educational process: (a) The Ministry of Education; (b) parents; (c) students; (d) teachers; (e) classrooms; and (f) schools. To bring initial understanding to this complex phenomenon, it is important that we examine each of the contributing players in the education process.

The education system of The Bahamas is mandated through its goals to provide educational opportunity for all students from age 5 to 16 years. For example, the third goal of the Department of Education for 1996/2000 stated that it would "...ensure that all secondary students are sufficiently challenged to develop and utilize their skills, thereby maximizing their potential. This process should serve as a foundation and preparation for the world of work and further education”. (Ministry of Education and Training, 1996, p. 4) Because the Education Act (1962) gave the Ministry of Education the ultimate authority for the education of our children, we will begin by examining its contribution.

\section{THE MINISTRY OF EDUCATION ${ }^{2}$}

The Bahamas Government, through the Ministry of Education provides public education for the 30 inhabited islands of The Bahamas. More recently, the islands were divided into school districts with a district superintendent responsible for each district. In addition, school boards were elected to manage the secondary schools in New Providence. Despite these changes, Ministry of Education is still ultimately responsible for the curriculum of the schools. Although the curriculum for mathematics as well as for the other subjects up to Grade 9 may be available in government public schools, only the Curriculum Guidelines Revised Scope and Sequence (2001) is available for Senior Secondary Mathematics (Grades 10, 11, and 12). The completed

\footnotetext{
${ }^{2}$ The Ministry of Education has undergone several name changes throughout the years: Ministry of Education and Training, Ministry of Education, Science and Technology, Ministry of Education and Culture, Ministry of Education, Youth and Sports, etc. In this paper we will simply use Ministry of Education.
} 
mathematics curriculum for Grades 10 to 12 is still not available in the public schools.

In addition to this overreaching goal of the education system, Ministry of Education has supported its goal for secondary education by stating specific objectives for each subject in the school curriculum. The objectives for mathematics indicated that the mathematics programme must strive to help students acquire skills necessary to become mathematically competent in both the national and international arena. Students should be able to analyze problems, make predictions, decide on a strategy and generate solutions. Outlined in the 1996 Ministry of Education and Training report was the notion that mathematics activities should emphasize understanding rather than merely pencil-and-paper computational drills and practice. Additionally, the students in mathematics classrooms should be allowed to explore, to evaluate, to reason logically, to conjecture, to think critically, to solve non-routine problems, and to communicate about and through mathematics. However, the Bahamas General Certificate of Secondary Education: Report on the June 2005 examination: mathematics showed that candidates taking the exams were deficient in many of the basic areas such as fractions, rounding, metric units, reverse percentages, algebra, and geometry.

Furthermore, the report stated that students were required to have strong reading and comprehension skills in order to achieve a B or C on the BGCSE examination. But the results showed that only $25.46 \%$ of the students taking mathematics had strong reading and comprehension skills. Also, according to the report, "Individual candidates performed at varying levels according to their ability and level of readiness. Unfortunately, there are still too many candidates performing at a below average ability range. Candidates need to be screened more thoroughly." (Ministry of Education, Science and Technology, 2005, p. 1). The report implied that the majority of students failed to meet the level of competency mandated by the Ministry of Education in mathematics.

According to the Ministry of Education and Training (1998) report, results of the BGCSE mathematics examinations for the 1997-1998 school year revealed that the national average for BGCSE mathematics had infact increased from $\mathrm{F}+$ in 1993 to $\mathrm{E}+$ in 1998. Grades ranged from A (highest) to $G$ (lowest), with a grade of $U$ for unsuccessful, indicating failure to achieve even the lowest grade of $\mathrm{G}$. Can anyone remember that the national average was D in 2003 and 2004? So why was there so much talk about the national average being a D in 2005? In 2003 the public secondary schools were divided into junior and senior high schools again. Hopefully, this move will positively affect education in general and the results of the BGCSE examinations in particular.

An analysis of mathematics grades in the 2005 report for the years from 2003 to 2005 (see Figure 2) showed that the number of students receiving grade A increased in 2004 and decreased in 2005 while grade $\mathrm{B}$ remained relatively consistent. The number of students receiving $\mathrm{C}$ remained relatively constant from 2003 to 2005. The number of students receiving D increased in 2005 while the number of students receiving $\mathrm{E}, \mathrm{F}$, or $\mathrm{G}$ remained too high. The number of students receiving $\mathrm{U}$ decreased in 2005.

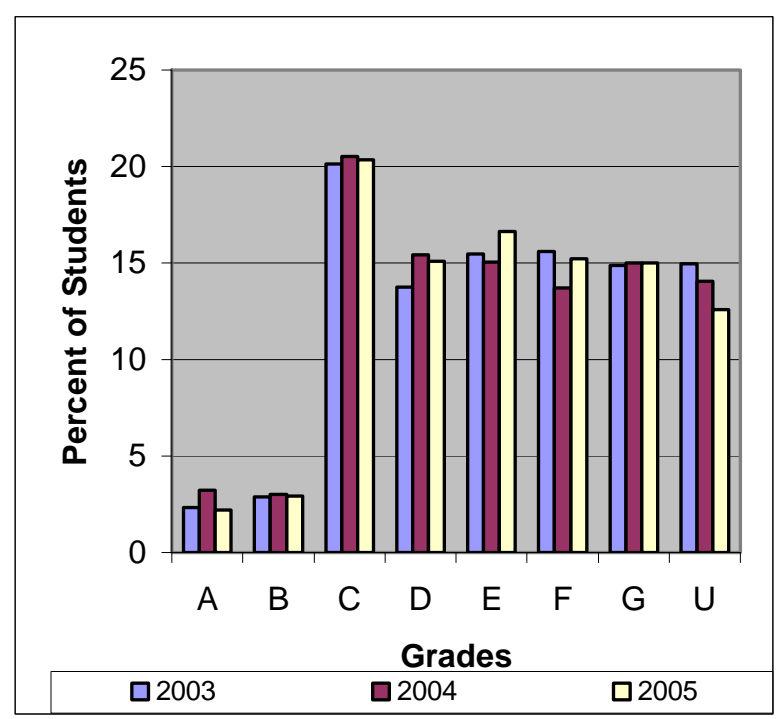

Figure 2. Mathematics Grades 2003-2005

Has the Ministry of Education fulfilled its obligation to our children? Collie-Patterson (1999) found that it has provided many of the opportunities that students needed in order to achieve academically. However, there are some shortcomings: insufficient trained mathematics 
teachers, the absence of a full-time mathematics education officer for over three years; no mathematics curriculum for Grades 10, 11, and 12; inability to demand that challenged teachers to upgrade themselves and remain current in their areas of study through professional development activities; and too many teachers being required to teach in areas in which they are not trained.

The Ministry of Education cannot work alone in achieving its goals, but must rely on the participation of other players, in particular, the parents.

\section{PARENTS}

Bahamian parents should consider the following questions that determine how involved they have been in the education of their children: (a) Do you discuss your children's school work with them? (b) Do you help your children with their homework or seek private tutoring for them? (c) Do you allow your children to work outside the home during the week? (d) Do you pick up your children's report cards? and (e) Do you attend parent-teacher meetings regularly? ColliePatterson (1999) asked the above five questions to 1036 students: 999 students responded to question (1) with a mean of 2.36 and standard deviation of 0.96 on a scale of one to four; 996 students responded to question (2) with a mean of 0.08 and standard deviation of 0.27 on a scale from of zero to one; 952 students responded to question (3) with a mean of 0.65 and standard deviation of 0.48 on a scale of zero to one; 997 students responded to question (4) with a mean of 3.43 and standard deviation of 0.97 on a scale of one to four; 1,001 responded to question (5) with a mean of 1.76 and standard deviation of 0.86 on a scale of one to four.

This result shows that students indicated that just over half of the parents discussed their children's school work with them but many parents did not. Very few parents sought help for their children when they were unable to help them. Less than $50 \%$ of the parents attended PTA meetings. Too many students were allowed to work outside the home during the week. Although many parents picked up their children's report cards, too many of them did not.

Parental involvement is an issue in education today and has been for many years. Parental involvement is so important to the educational process that the lack of it provides a major challenge to educators, policy makers and legislators (Leuder, 1998). In a study conducted at George Washington High School in Marietta, Georgia, Koerner (1999) reported that parental involvement had a major impact on student achievement. Other studies have provided evidence of the link between parental involvement and student achievement. "The 1998 Metropolitan Life Survey of the American Teacher found that 87 percent of students who earn A's and B's cited their parents' involvement and aid as vital to their success, while half of those earning C's or worse said their parents had no interest in their schools" (Koerner, 1999, para. 3).

According to Kober (1991), the large number of single parent families and the large numbers of children living in poverty place many stresses on the home environment. Although some of these stresses cannot be changed, all parents can make a difference in their children's school performance by giving support and being involved in their children's education. For example, they can meet with teachers regularly; establish rapport with teachers; support teachers' instruction by continuing practice of skills at home; talk daily with the children about what they are doing at school; support children's interests outside of school; periodically volunteer at school; set regular times for homework at home; assist with gathering materials for projects; limit the amount of television watching during the school week; provide healthy meals; read to the children; and model life-long learning behaviour in the home.

Considering the importance of parental involvement in student achievement in the United States, it is important that Bahamian parents become involved in their children's education. Therefore, examination of the effects that parents have on their children, and the importance of parental involvement in the children's educational process, along with the responses by students to the questions posed earlier, suggested that Bahamian parents also contribute to the national average of D on the BGCSE. However, parents are not alone. The students are also a part of the educational process, so let us now examine the important role they play. 


\section{STUDENTS}

Students are so important to the learning process that no learning could take place without their involvement, whether as a passive observer or a willing participant. As early as 1963, Carroll indicated that students were extremely important in the learning process. He identified five constructs that were important to school learning-aptitude, opportunity to learn, perseverance, quality of instruction, and ability to understand instruction. Three of the five constructs identified by Carroll—aptitudes, ability to understand instruction, and perseverancewere directly related to students and were necessary factors that affected students' learning. A student's level of engagement is a direct result of his or her involvement in the learning process. This is also directly related to the student's prior knowledge in the area of study.

A student's prior knowledge in mathematics is considered as the best indicator of future proficiency in that area and is determined by a combination of factors relating to the student's home background and schooling history (Leder, 1992). To be successful, students must enter school ready to learn; parents must provide them with the necessities of life such as food, protection, clothes, shelter, and love as well as "the guidance and richness of experience needed to succeed in school and proceed, with confidence, in life" (p. 8). Additionally, students must have a solid foundation in the relevant school disciplines in order to achieve in those areas (Boyer, 1993).

The hostile environment in which many students from low-income families are forced to live causes many of them to "suffer stressful racial and ethnic tensions, instead of developing a sense of belonging” (Comer, 1994, p. 23). Adults, such as parents, teachers, and administrators, involved in the lives of students should communicate high expectations to all students. Regardless of their backgrounds, students need to know what the adults in their lives expect of them. If students are expected to show high academic performance they will do so. Similarly, if students are expected to show low academic performance, they will do so (Comer, 1994). Students should also be engaged in their learning as well as other school activities (McGraw, 1999).
Increasing difficulty with academic work, and questionable or difficult relationships with others force children to choose between the cultures of the school and the social structure of the society. "Involvement in the drug culture, teenage pregnancy, delinquency, [gangs], and crime increase and become more attractive possibilities as the probability of school and mainstream fades" (Comer, 1994, p. 31). A crucial element in motivating students to learn is the emotional bond they formed with their teachers (Waller, 1932). "The principal reason for today's academic deficiency is that mass culture has undermined young people's desire to learn and their respect for parents and teachers” (Ruggiero, 1998, p. 8).

Collie-Patterson (1999) established that students' characteristics consisting of student's prior ability, attitude toward school, socioeconomic status and parental involvement made the largest contribution (60\%) to mathematics achievement. Taken individually, the effect size indicated that student's prior ability made the largest contribution (48\%) to mathematics achievement. One thousand and one students responded to the statement: "Students hear what they do right, not their mistakes", with a mean of 2.20 and standard deviation of 1.24 on a scale of one to five. This suggests that over $68 \%$ of the students disagreed with this statement suggesting that teachers and students need to become involved in more positive dialogue. Students need to know what they are doing right as well as what they are doing wrong.

Since students are so important to the learning process, it is necessary that they be engaged in their learning. Also, prior ability and attitude toward school are very important. Therefore, both teachers and students should always keep in mind that in order to achieve, a solid foundation is necessary. In addition, Bahamian students need to develop good study habits and spend more time doing homework. From my experience as a teacher, Bahamian students have contributed greatly to the national average of $\mathrm{D}$. However, teachers are also involved in the educational process. So let us examine their contribution.

\section{TEACHERS}

Researchers in mathematics education have observed that in order for students to achieve 
academically, teachers must be prepared educationally and psychologically, and teach effectively. "Teachers must have a high level of content knowledge and pedagogical skills and be prepared to utilize the most effective instructional materials, assessment strategies and educational technologies. Teacher's education includes both pre-service and in-service education” (U.S. Dept. of Education \& National Science Foundation, 1998, p. 4). When a person enters the teaching arena he or she is involved in a lifelong learning process that began before he or she entered a college of education and continues throughout his or her career (Irwin, 1994).

George Bernard Shaw wrote nearly a century ago "He who can, does. He who cannot, teaches" (Shulman, 1986, p. 9). Ever since, teachers have had to show that "they can" because most people believe they cannot. Consequently, teachers need to be highly qualified in the content area that they are expected to teach. Teachers' content knowledge is categorized as: (a) subject matter content; (b) pedagogical content; and (c) curricular content. Content knowledge is defined as "the amount of and organization of knowledge per se in the mind of the teacher". (p. 9) Pedagogical content knowledge includes subjectmatter knowledge that is needed for teaching, as well as representation and formulation of the subject to make it comprehensible to others; how best to present specific topics to students so that they will understand; and how to use students' prior knowledge in the presentations of familiar topics and lessons. Curricular knowledge is identified as having full knowledge of the type of programs designed for teaching particular subjects and topics at given levels, the kind of instructional material available for those programs, and the ability to choose the appropriate materials to implement the programs successfully (Shulman, 1986). "Mathematical ideas, facts, and concepts, and the relationships between and among them must be taught, but the teacher must also be concerned with the processes of doing and creating mathematics. Clearly, teachers must know mathematics well in order to teach it well" (Brown \& Baird, 1993, p. 247).

Furthermore, a research study conducted by Lee Shulman and his associates at Stanford University on teachers' knowledge of mathematics and mathematics teaching found that knowledge of mathematics influences how mathematics is taught (Brown \& Baird, 1993). Teachers with high content knowledge are engaged in more conceptual teaching and conform more fully to the National Councils of Teachers of Mathematics (NCTM) standards than teachers with lower content knowledge whose teaching tend to be more rule based (Cherkas, 1992).

Before the early 1970s, research focused on the process variables and the relationships among variables, demographics, and classroom process. Recently, however, the focus changed from the process of teaching to the product of teaching. Emphasis on product teaching changed the focus from teachers' behaviors to what the teachers are doing to promote students' achievement (Ornstein, 1991). The new trend in mathematics research places mathematics teachers in a position where they must strive to be effective classroom teachers in order to promote student learning. In order for students to learn, the students must be taught. However, more than teaching is necessary for students to learn (Slavin \& Braddock, 1994). Consequently, mathematics teachers ought to have a sound understanding of the mathematics they are required to teach and keep abreast of the continuous changes that are occurring in mathematics and in education.

The Bahamian society has judged teachers by the results of the Bahamas Junior Certificate (BJC) and BGCSE results of the students they teach. However, teachers are not entirely to be blamed for the dismal results of these examinations. The shortage of trained teachers in areas such as mathematics has led to the hiring of teachers to teach subjects that they are not trained to teach. As a result, in-service training is necessary to assist the number of unqualified and underqualified subject teachers and provide support for others. But unlike other countries where teachers are required to upgrade themselves periodically in order to keep their certification valid, education officials in the Ministry of Education have indicated to this researcher that they cannot force unqualified or under-qualified teachers to attend professional development programmes. In Japan, for example, not only is teachers' knowledge of mathematics content important, but teachers are required to participate in extensive professional 
development programmes. Japanese teachers are also required to participate in ongoing training; and teachers are given the opportunity to observe each other in the classroom. Interaction with each other is compulsory. The teachers are given time to learn and plan together and share ideas with other teachers (Kinney, 1998).

In the Bahamas, on the other hand, teachers are not required to participate in professional development programmes and when they are asked to participate the ones who volunteer are usually not those who need to attend. Teachers who are unable to return to college to be retrained would also benefit greatly from well organized professional development programmes (Monk \& King, 1994).

In addition, teacher collaboration is one of the most economical and most powerful methods of professional development. Teachers working together in collaboration greatly influence students' achievement, behaviors, and attitudes. Collaborations also reduce isolation and lead to an increase in effectiveness and feelings of satisfaction. 'Teachers' teamwork makes complex tasks more manageable, stimulates new ideas, and promotes coherence in a school's curriculum and instruction. In short, the collaborative environment fosters continuous learning by the teachers, that enhances their effectiveness in the classroom" (Inger, 1993, p.1).

Collie-Patterson (1999) asked 1036 students to respond to the following statements: (a) "Teachers and students here trust one another", 1004 responded to the statement with a mean of 2.18 and standard deviation of 1.12 on a scale of one to five; (b) "Teachers at this school treat students with respect”, 999 students responded to the statement: with a mean of 2.59 and standard deviation of 1.21 on a scale of one to five. In response to the above questions the students disagreed with the statements indicating that there was a reported lack of trust between teachers and students, a serious breach which should be addressed by Bahamian educational institutions. Nevertheless, the findings of this study showed that teachers played a small but statistically significant role in their students' mathematics achievement.

Although the set of teachers' characteristics that included professional development, teaching experience, and educational background was significantly related to mathematics achievement, teachers contributed only $8 \%$ to students' mathematical achievement. It is reasonable, therefore, to conclude that teachers also contribute to the national average of $\mathrm{D}$. Teachers cannot do it alone so they need help as they labour in the trenches. For meaningful learning to take place, the classroom needs to be conducive to teaching and learning. We will now examine the classroom to determine its contribution.

\section{CLASSROOM}

In Goodlad's “A Study of Schooling” (1983) observers spent three days in each of the 5000 classrooms in the sample population observing the classroom activities of students and teachers. They reported that $81 \%$ of the time in the hightrack mathematics classes and $78 \%$ of the time in the low-track mathematics classes were spent on instruction. Additionally, the observers found that students from low-track classes were learning less. Furthermore, they also found 1\% of high-track mathematics students and $4 \%$ of low-track students were notably off-task. The percent of time students spent off-task was relatively low but the low-track students were observed off-task four times as often as the high track students in mathematics classes (Goodlad, 1983). In addition, teachers reported that expectation time for homework was 38 minutes for high-track mathematics classes and 27 minutes for low-track mathematics classes (Oakes, 1985). This situation is also relevant in the Bahamian context today. The percentage may be even higher in the Bahamian classroom.

The learning opportunities that students are provided within the classrooms were greatly influenced by the interaction with their teachers. So, students who are less able and eager to learn will affect a teacher's willingness or ability to provide them with the best learning opportunities (Oakes, 1985). Consequently, many teachers of low-track students provide students with substandard versions of the academic curriculum; courses that are relevant only to specific vocational training; less time on actual instructional and learning activities; inferior textbooks and laboratory sessions in science; and 
a decrease in homework expectation when compared with higher-tracked students, therefore, allowing students more time for distraction outside of school (Sedlak, Wheeler, Pullin \& Cusick, 1986; Slavin \& Braddock, 1994).

In order for instruction to be meaningful, the subject-matter must invoke active inquiry and interaction based on the student's prior ability (Miller, 1990). Teachers in high ability classes are more apt to encourage independent questioning and critical thinking, organize tasks better, and give the students a greater variety of tasks than teachers in the low ability classes. In addition, teachers in the low ability classes are more interested in students following directions, being on time, and sitting quietly (Oakes \& Lipton, 1994). In spite of the disparity, the level of engagement in academic learning is influenced by the "extent to which receiving a diploma has educational, personal, or economic meaning to both its possessor and the world of work or future education, which must either accommodate or ignore the student”' (Sedlak et al., 1986, p. 19).

Oakes (1985) identified six characteristics and behaviors that she considered to be effective instructional behaviors: (a) presenting lessons clearly ; (b) using of different types of activities, materials, texts and instructional strategies during lessons; (c) showing enthusiasm during instruction; (d) making task instruction oriented, achievement oriented, and businesslike; (e) avoiding the use of strong criticism of students; and (f) exposing students to the materials they are expected to learn.

Successful teachers should coordinate many elements in their instruction practices in order to provide students with success and satisfaction. These elements should include making sure that students understand directions before they begin an assigned task; maintaining appropriate pace; keeping students involved; using positive reinforcement and justifiable recognition; varying instructional strategies; alternating lengths of activities; and giving regular and consistent feedback (Goodlad \& Klein, 1975). In spite of any difficulties that teachers may encounter, "all students must feel free to ask questions, share what they know and admit what they don't know, read their writing, make mistakes, take stands and change stands, grow as thinkers” (Cone, 1994, p. 301).

Collie-Patterson (1999) established that classroom's characteristics contributed $36 \%$ to mathematics achievement indicating that the classroom is a significant contributor, and as a result, must function effectively. But in order to achieve the best results in the classroom, the school must be effectively administered. There are many instances where teachers are afraid to take control of their classrooms and discipline unruly students. Until teachers are comfortable enough to control their classrooms and receive the support they need, the classroom will continue to contribute to the national average of D. Let us consider the last major contributor in the educational process, the school.

\section{SCHOOL}

An effective school is judged by the following characteristics: clearly stated goals (Brookover \& Lezotte, 1976); communication of expectations of both goals and behaviors from both students and teachers (Duckett, 1980); setting high achievement goals for students (Edmonds, 1979); monitoring of students' and teachers' progress (Brookover \& Lezotte, 1976); and the assumption of responsibility for the achievement of stated goals (Edmonds, 1979). A synthesis of research on school effectiveness by Rogus (1983) showed that two of the central components of successful schools are expectations of, and communication with the members of the school community. Once these characteristics of effective schools were identified, researchers began to examine public schools to determine whether or not they contained similar characteristics.

Unfortunately, many of the characteristics that researchers identified as essential for promoting students' learning were not found in many public schools. According to Reilly (1995), researchers have identified the following five basic reasons for public school failure: (1) lack of clearly defined mission, (2) the lack of educational reforms which utilize effective planned strategies for change, (3) the lack of an effective and coordinated governance and control mechanism, (4) the lack of an organizational and administrative structure that maximizes learning opportunities, and (5) the lack of a core 
knowledge base for teachers. Although the mentioned studies were not conducted locally, they are applicable to the Bahamian school system. Adding to this dilemma, schools have the dual, conflicting role of reflecting and reproducing the society while at the same time changing the society as it exists in favor of what it should be (Oakes, 1985). No wonder schools are perceived as failures.

Collie Patterson (1999) established that the set of school characteristics contributed $12 \%$ to mathematics achievement. But in the Bahamas we are aware that students are engaged in fighting, carrying weapons, drugs and drug activities at school. These activities hamper teaching and learning. Therefore, it is reasonable to suggest that the school also contributes to the national average of $\mathrm{D}$.

\section{CONCLUSION}

This paper has shown that the major contributors to the national average of $\mathrm{E}+$ in mathematics, and by extension, D in the BGCSE examinations are the Ministry of Education (representing the Government of The Bahamas), parents, students, teachers, classrooms, and schools. Each of these players has a significant role and although they have contributed to the achievement of some students, they need to do more in order to help others. Unless we can help more students to achieve, the national average will remain a D. Furthermore, the students are the most important player in their educational achievement but for the most part the majority of them seem disengaged. Collectively, all the players in the education process need to find ways to get the students interested in their own education.

\section{REFERENCES}

Boyer, E. L. (1993). Ready to learn: A mandate for the nation. Princeton, NJ: Carnegie Foundation for the Advancement of Teaching.

Brookover, W. B., \& Lezotte, L. W. (1976, September). Elementary school social climate and school achievement. Paper presented at the annual meeting of the American Sociological Association, New York. (ERIC Document Reproduction Service No. ED131602.

Brown, C. A., \& Baird, J. (1993). Inside the teacher: Knowledge, belief, and attitudes. In P. S. Wilson \& $\mathrm{S}$. Wagner (Eds.), Research ideas for the classroom: High school mathematics, (pp. 245259). New York: Macmillan.

Carroll, J.B. (1963). A model of school learning. Teachers College Record, 64(8), 723-733.

Cherkas, B. M. (1992). A personal essay in math? College Teaching, 40(3), 83-86.

Collie-Patterson, J. M. (1999). The effects of four selected components of opportunity to learn on mathematics achievement of grade 12 students in New Providence, Bahamas. (Doctoral dissertation, University of Southern Mississippi, 1999).

Dissertation Abstracts International, AAT 9960881

Comer, J. P. (1994). Home, school, and academic learning. In J. I. Goodlad \& P. Keating (Eds.), Access to knowledge: The continuing agenda for our nation's schools. (Rev. ed.), pp. 23-42. New
York: College Board Publications

Cone, J. K. (1994). Learning to teach the untracked class. In J. I. Goodlad \& P. Keating (Eds.), Access to knowledge: The continuing agenda for our nation's schools. (Rev.ed.), pp. 297-319. New York: College Board Publications.

Duckett, W. R. (1980). Why do some urban schools succeed?: The Phi Delta Kappa study of exceptional urban elementary schools. Bloomington, IN: Phi Delta Kappa.

Edmonds, R. (1979). Effective schools for the urban poor. Educational Leadership, 37(1), 15-18, 20-24

Education Act, 1962, [CH. 46], (Bahamas)

Goodlad, J. I. (1983). A study of schooling: Some findings and hypotheses. Phi Delta Kappan, 64(7),465-70.

Goodlad, J. I., \& Klein, M. F. (1975). The conventional and the alternative in education. Berkeley, CA: McCutchan.

Inger, M. (1993). Teacher collaboration in urban secondary schools. ERIC/CUE Digest, Number 93. ERIC Document Reproduction Service No. ED363676. Retrieved from ERIC database.

Irwin, K. (1994). Ongoing development as a teacher of mathematics. In J. Neyland (Ed.), Mathematics education: a handbook for teachers. Volume 1. (pp. 367-374) Wellington, N.Z.: Wellington College of Education. 
Kinney, C. J. (1998). Building an excellent teacher corps: How Japan does it. American Educator, 21(4), 16-23.

Kober, N. (1991). What we know about mathematics teaching and learning. EDTALK. (ERIC Document Reproduction Service No. ED343793). Retrieved from ERIC database.

Koerner, B. I. (1999, January 18) Parental power. US News and World Report, 126, 72-76. Retrieved from http://www.usnews.com/usnews/ culture/articles/990118/archive_000089.htm

Leder, G. C. (1992). Mathematics and gender: changing perspectives. In D. A. Grouws (Ed.), Handbook of research on mathematics teaching and learning. New York: Macmillan.

Leuder, D.C. (1998). Creating partnerships: An educator's guide. Lancaster, PA: Technomic.

McGraw, D. (1999, January 18). Inspired students. U.S. News \& World Report. Retrieved from http://www.usnews.com/usnews/culture/articles/99 0118/archive_000081.htm

Miller, R. (1990). What are schools for: holistic education in American culture. Brandon, VT: Holistic Education Press.

Ministry of Education and Training. (1996). Teaching in the public education system in the Bahamas. Nassau, Bahamas: Author.

Ministry of Education and Training. (1998). Bahamas General Certificate of Secondary Education: Report on the June 1998 examination : mathematics. Nassau, Bahamas: Government Printing.

Ministry of Education and Training. (2001). Curriculum guidelines: Revised scope and sequence. Unpublished manuscript.

Ministry of Education, Science and Technology. (2005). Bahamas General Certificate of Secondary Education: Report on the June 2005 examination: mathematics. Nassau, Bahamas: Government Printing.

Monk, D. H., \& King, J.,A. (1994). Multilevel teacher resource effects in pupil performance in secondary mathematics and science: The case of teacher subject matter preparation. In R.G. Ehrenberg (Ed.), Choices and consequences: Contemporary policy issues in education. (pp. 29-58). Ithaca, NY: ILR Press.
Oakes, J. (1985). Keeping track: How schools structure inequality. New Haven: Yale University Press.

Oakes, J., \& Lipton, M. (1994). Tracking and ability grouping: A structural barrier to access and achievement. In J. I. Goodlad \& P. Keating (Eds.), Access to knowledge: The continuing agenda for our nation's schools. (Rev.ed.), (pp. 187-206). New York: College Board Publications.

Ornstein, A. C. (1991). Teacher effectiveness research: Theoretical considerations. In H. C. Waxman \& H. J. Walberg (Eds.), Effective teaching: Current research, (pp. 63-80). Berkeley, CA: McCutchan.

Pinder, M. N. (2005, August 19). "Education official says BGCSE standard will not be lowered”. The Bahama Journal. Retrieved from http://www.jonesbahamas.com

Reilly, D. H. (1995). How to have successful schools!: What parents and teachers need to know to improve children's learning. Lanham, MD: University Press of America.

Rogus, J. F. (1983). How principals can strengthen school performance. NASSP Bulletin, 67(459), 1-7.

Ruggiero, V. R. (1998). Changing attitudes: A strategy for motivating students to learn. Boston: Allyn and Bacon.

Sedlak, M. W., Wheeler, C. W., Pullin, D. S., \& Cusick, P. A. (1986). Selling students short: Classroom bargains and academic reform in the American high school. New York: Teachers College Press.

Shulman, L. S. (1986). Those who understand: Knowledge growth in teaching. Educational Researcher, 15(2), 4-14.

Slavin, R. H., \& Braddock, J. H. (1994). Ability grouping: On the wrong track. In J. I. Goodlad \& P. Keating (Eds.), Access to knowledge: The continuing agenda for our nation's schools. (Rev.ed.,), (pp. 289-296 ). New York: College Board Publications.

U.S. Department of Education, \& National Science Foundation. (1998). An action strategy for improving achievement in mathematics and science. Retrieved from http://www.ed.gov/pubs/12TIMSS/index.html.

Waller, W. (1932). The sociology of teaching. New York: Russell \& Russell. 